This item was submitted to Loughborough's Research Repository by the author.

Items in Figshare are protected by copyright, with all rights reserved, unless otherwise indicated.

\title{
The impact of social identity and social dominance on the regulation of human growth: A viewpoint
}

\section{PLEASE CITE THE PUBLISHED VERSION}

https://doi.org/10.1111/apa.14970

\section{PUBLISHER}

Wiley

\section{VERSION}

AM (Accepted Manuscript)

\section{PUBLISHER STATEMENT}

This is the peer reviewed version of the following article: Hermanussen, M., Bogin, B. and Scheffler, C., 2019. The impact of social identity and social dominance on the regulation of human growth: A viewpoint. Acta Paediatrica, 108(12), pp. 2132-2134, which has been published in final form at https://doi.org/10.1111/apa.14970. This article may be used for non-commercial purposes in accordance with Wiley Terms and Conditions for Use of Self-Archived Versions.

\section{LICENCE}

CC BY-NC-ND 4.0

\section{REPOSITORY RECORD}

Hermanussen, M, Barry Bogin, and C Scheffler. 2019. "The Impact of Social Identity and Social Dominance on the Regulation of Human Growth: A Viewpoint". Loughborough University. https://hdl.handle.net/2134/13237979.v1. 


\title{
The impact of peer group and social dominance on the regulation of human growth. A viewpoint.
}

\author{
Hermanussen $\mathrm{M}^{1}$, Bogin, $\mathrm{B}^{2}$, Scheffler $\mathrm{C}^{3}$ \\ 1 Aschauhof 3, 24340 Eckernförde - Altenhof, Germany \\ 2 School of Sport, Exercise \& Health Sciences, Loughborough University, LE11 3TU, \\ UK \\ 3 University of Potsdam, Human Biology, 14469 Potsdam, Germany
}

The clinical audience is wedded to the idea that stunting is nutritional. Also among the nutrition community there is "convergence on the use of length-for-age as the indicator of choice in monitoring the long-term impact of chronic nutritional deficiency" [1]. These discernments are puzzling. The associations between nutrition and growth, and also those between water, sanitation, hygiene (WASH) and growth, are anything but obvious. Sguassero et al. [2] meta-analyzed community-based supplementary feeding in children under 5 years in low- and middle-income countries and concluded that supplementary feeding has a negligible impact on child growth. A systematic scoping review of interventions promoting better nutrition for infants and children living in slums in low income nations identified 22 unique studies of which only 16 were assessed effective [3]. Ten of the effective studies increased body mass, especially fat, but had either no impact on stunting, or were associated with greater stunting. The six interventions with a positive impact on stunting had small effects, with the mean improvement close to the typical value for measurement error. A Cochrane systematic review of interventions to improve WASH practices and their relation to nutritional status [4] identified 14 studies involving 22,241 children at baseline and nutrition outcome data for 9,469 children, with no significant effects of WASH interventions on any of the measures of growth in children under 5 years.

The observation that nutrition and growth in height are not necessarily intertwined, is not new. In this journal in 2018 we reviewed studies of 'forgotten' (German-language, print-only) 19th and early 20th century literature of weight and height growth of malnourished school-age children during re-feeding. Height catch-up after starvation was greater than catch-up reported in modern nutrition intervention studies, and allowed for unimpaired adult height, but this was only for children from intact families of middle-class social background. In contrast, orphans and children from poor social background failed to recover and paralleled the growth patterns observed in children of modern middle and low-income countries. We noted that in $1935 \mathrm{Koch}, \mathrm{a}$ pediatrician, noted that even without food some children grew: "...nor does particular abundance of food appear to be a prerequisite for growth at all. Size recklessly increases even during marked undernutrition ... . until the body has wasted its last depot. One might talk about parasitic growth in length".

According to modern growth standards, during and shortly after World War I European children grew poorly; many of them were "stunted". But what is stunting? Between the Neolithic period, $5000 \mathrm{BC}$ to $3000 \mathrm{BC}$, and the Middle Ages, average male height ranged between some 165 and $171 \mathrm{~cm}$, female height between 151 and $161 \mathrm{~cm}$. Up to $50 \%$ of these people were stunted. Egyptian pharaohs, Minoan kings, and Maya kings barely reached average WHO reference. The tallest medieval kings, 
we may cite Charlemagne or English monarchs were not taller than modern Dutchmen.

Is stunting a matter of biology or of history? Homo sapiens had never been taller than today. Meanwhile, 175 out of 200 male populations reach average height above 165 $\mathrm{cm}$, half of them more than $171 \mathrm{~cm}$, and surpass the millennia-old European average [5]. Is it meaningful to ask, why are people short, or better, why did modern people so suddenly increase in height?

We focus on:

(1) why are people living in the same community, so similar in height? and

(2) why did modern populations, within a few decades, almost explosively increased in height?

Humans are social; social communities rely on signals. Dominance, subordination, reproduction and other behaviors are linked with physical features such as body size, fat pads, coloring, distribution of hair and many others. It is not far-fetched to assume that this also applies to humans. It has been investigated, but is still widely neglected in recent biomedical studies of human growth and development.

Social identity theory considers that portion of an individual's self-concept that is derived from perceived membership in a relevant social group. The system of cognitive representations of self is based upon comparisons with other people and relevant to social interaction. Peer group membership correlates with emotional, evaluative and other psychological parameters. The concept of a 'self-categorization theory' tries to explain the psychosocial basis of group phenomena, and to identify the mechanisms by which individuals become unified into psychological groups. Group identification and identity signalling shape common goals and social norms. This is not limited to movements, facial expressions and clothing. Psychologists have long speculated on how socioeconomic inequalities perpetuate across generations. Biologists have long known that bigger individuals have high social status. Human are no exception and taller people dominate in earnings, political power, and even benign social situations such as 'giving way' within limited space. The newest experimental and observational evidence finds that, "...higher-class individuals were more overconfident; overconfidence, in turn, made them appear more competent and more likely to attain social rank... [and that] compared with individuals with relatively low social class, individuals with relatively high social class have a greater desire for social rank, which in turn promotes overconfidence" [6].

Emotional desires can be transduced by the neuroendocrine system and behaviour into biology. Psychosocial growth restriction is well known. We reported that migrants adjust in height towards their hosts [7] and reviewed the findings by others that described the spread of obesity in social networks, the similarity in weight among people who know each other, and the remarkable evidence that people of the same community are similar in height. People living among tall people, are tall; people living among short people, are short. Swiss military conscripts are as tall as conscripts of neighbor districts. The association decreases with increasing road distance. The coefficients of variation for height quite consistently stay close to or below $3.5 \%$ regardless of the historic or geographic changes of the mean values of height. Similar observations were reported from Norway and Japan. We named the effect of social interaction between members of the same group, on growth and 
height "community effect in height" [8]. Some of this effect may be ascribed to nutrition and disease, most cannot. People can be short simply because their neighbors are short.

What is the mechanism for this community effect? Size signals status. Being short signals subordination, tallness is associated with greater social power and socioeconomic status. Aristocrats are usually tall. Komlos and colleagues studied growth of German boarding schoolboys educated in the Grand Ducal Carlsschule in Stuttgart. The boys aged 6-23 years, were measured at irregular 3-12 monthly intervals between 1771 and 1793. At age 18 years, mean height was $165.2 \mathrm{~cm}$ (min $147.4 \mathrm{~cm}$ - $\max 182.6 \mathrm{~cm}$ ). Boys from high aristocratic families know about their social position and strategically adjust in height. They were some 10 to $15 \mathrm{~cm}$ taller and matured 1-2 years earlier than their low aristocratic and bourgeois classmates, even though they shared lifestyle and the same nutritional conditions. Strategic growth adjustments are not limited to humans and have been shown in many social mammals and particularly well been studied in meerkats. In these animals, social dominance itself is a growth stimulus. Meerkats live in hierarchal groups of some 30 50 individuals. The social rank of an individual is based on age and weight. Slowly growing animals may lose their dominant position to faster growing younger "challengers". Meerkats that "acquire dominant status, show a secondary period of accelerated growth whose magnitude increases if the difference between their own weight and that of the heaviest subordinate of the same sex in their group is small" [9]. As in many mammalian species status/growth is usually explained by unequal access to resources stimulating growth of subordinate members by additional feeding challenges dominant members. When they feel "threatened of being displaced", they further increase in size, a phenomenon the authors called competitive growth strategies and strategic growth adjustments.

Strategic growth adjustments can be observed in numerous sets of historic body height data. Whenever revolutions destabilize social structures, or when democracy facilitates social transition, the adolescents of the lower social strata tend to grow taller, followed by the adolescents of the upper strata who appear to readjust height at taller level similar to the observations in meerkats that feel "threatened of being displaced". We consider the marked height trends in modern Europeans an expression of strategic growth adjustments at the population level.

The secular height trend of the tallest Europeans, the Dutch, started already shortly after the 1848 revolution. King William II had agreed on several demands of the liberal parliamentary opposition that laid the basis for the present parliamentary democracy in the Netherlands. Similar trends in Germany did not occur until World War I when the German Empire and its rigid social class-system collapsed followed by social upheaval, starvation, mass unemployment and political insecurity.

Pfaundler, a prominent German pediatrician, first mentioned "those unnaturally tall, asthenic children" whom he believed to exhibit pathology. The secular trend for increasing height in Japan from 1940-1975 was more rapid for lower social classes, with the upper classes maintaining and ever-decreasing average height advantage [10]. The lower-class increase was most intense from 1942-1958 when economic conditions and hunger were at their worst, but social-political liberalization was most active. From 1941 to1945 food production drastically decreased and in 1945 many people starved to death in urban areas. The nutritional level started to recover in 1949 and reached pre-war levels only in 1953. The impact of the deprivation during 
the war is seen in the average weight of the lower-class which remained constant between 1933-1944, even as average height 'recklessly' increases. In contrast to the lower-class, the average height of upper-class men declined for those born 1928-30. These privileged boys would have been entering puberty at the beginning of WW II, an age we proposed that is most sensitive to competitive growth strategies and strategic growth adjustments.

The current debate on stunting is dominated by observations from modern populations and narrowly defined nutritional causes. We are concerned that this view is too limited and excludes historic, social, emotional, and neuroendocrine perspectives. Likewise, hypotheses associating child stunting with developmental potential, human capital and risk of adult diseases should include competitive growth strategies and community effects on height.

Strategies for identifying growth inhibition due to malnutrition should be based both on anthropometric and the classic clinical indicators, including energy balance, fat depots, and carefully designed nutrition protocols. We question the current definition of stunting as prima facie evidence of malnutrition, and the inappropriate use of global growth standards to define nutritional adequacy in short, but otherwise apparently healthy and well-nourished children. These populations especially when raised in remote areas of former European colonies, form their own communities and may markedly differ in social and economic organization. Being short or tall may merely reflect differential effects of the community, that go beyond current ideas about growth inhibition due to social stress determined by the political systems, social conflict and lack of trust among social classes. Quite in contrast, community effects may also include the stimulation of growth due to social mechanisms that are still incompletely understood.

\section{Conflict of Interest statement - None}

Funding statement - No funding

Literature - a complete list of references from the authors to all the publications and ideas mentioned

1. Lartey A. What would it take to prevent stunted growth in children in sub-Saharan Africa? Proc Nutr Soc. 2015;74:449-53.

2. Sguassero Y, de Onis M, Bonotti AM, Carroli G. Community-based supplementary feeding for promoting the growth of children under five years of age in low and middle income countries. Cochrane Database Syst Rev. 2012; 6: CD005039.

3. Goudet SM, Griffiths PL, Bogin B, Madise NJ. Interventions to tackle malnutrition and its risk factors in children living in slums: a scoping review. Ann Hum Biol. 2016; 44: 1-10.

4. Dangour AD, Watson L, Cumming O, Boisson S, Che Y, Velleman, et al. Interventions to improve water quality and supply, sanitation and hygiene practices, and their effects on the nutritional status of children. Cochrane Database Syst Rev. 2013; 8: CD009382, doi: 10.1002/14651858.CD009382.pub2. 
5. NCD Risk Factor Collaboration (NCD-RisC). A century of trends in adult human height. Elife. 2016; 26;5. pii: e13410. doi: 10.7554/eLife.13410.

6. Belmi P, Neale MA, Reiff D, Ulfe, R. The social advantage of miscalibrated individuals: the relationship between social class and verconfidence and its implications for class-based inequality. J Personal. Soc. Psychol. Advance online publication. http://dx.doi.org/10.1037/pspi0000187

7. Bogin B, Hermanussen M, Scheffler $C$. As tall as my peers - similarity in body height between migrants and hosts. Anthropol Anz. 2018; 74: 365-376. doi: 10.1127/anthranz/2018/0828.

8. Aßmann C, Hermanussen M. Modeling determinants of growth: evidence for a community-based target in height? Pediatr Res. 2013 74(1):88-95. doi: 10.1038/pr.2013.50.

9. Huchard, E., English, S., Bell, M.B., Thavarajah, N. \& Clutton-Brock, T. (2016): Competitive growth in a cooperative mammal. Nature 533: 532-534.

10. Kouchi M. Secular Change and Socioeconomic Differencein Height in Japan. Anthropol. Sci. 1996; 104: 325-340. 